

\title{
ARTICLE
}

\section{Evaluation of Different Ni-Semiconductor Composites as Electrodes for Enhanced Hydrogen Evolution Reaction}

Received 00th January 20xx, Accepted 00th January 20xx DOI: $10.1039 / x 0 x \times 00000 x$

\author{
Melisa J. Gómez ${ }^{\mathrm{a}, \mathrm{b}}$, Victoria Benavente Llorente ${ }^{\mathrm{a}, \mathrm{b}}$, Andrew Hainer ${ }^{\mathrm{b}}$, Gabriela I. Lacconi ${ }^{\mathrm{a}}$, Juan C. \\ Scaiano, ${ }^{b}$ Esteban A. Franceschini ${ }^{a, b *}$, Anabel E. Lanterna ${ }^{b *}$
}

\begin{abstract}
The use of earth-abundant materials for designing efficient and stable electrocatalysts is of paramount importance to facilitate large-scale production of hydrogen. In this work we developed a new series of electrodes based on $\mathrm{Ni}$ semiconductor composites (Ni|SC) that are easy to synthesize (binder-free, economic and readily scalable method of synthesis), highly stable and active towards electrochemical hydrogen production under alkaline conditions. We showed the direct electrodeposition of composites ( $\mathrm{Ni} \mid \mathrm{SC}$ ) from nickel-Watts plating baths modified by the addition of $\mathrm{Nb}_{2} \mathrm{O}_{5}, \mathrm{Nb}_{3}\left(\mathrm{PO}_{4}\right)_{5}$, $\mathrm{Bi}_{2} \mathrm{O}_{3}$ and $\mathrm{WO}_{3}$ semiconductor particles. The electrodes were characterized by different techniques (electron and confocal microscopy, X-ray spectroscopy, X-ray diffraction, Raman spectroscopy, among others) before and after their electrochemical evaluation as catalysts for hydrogen evolution from water. In order to gain insights into their structureactivity relationship, the materials were also characterized by means of electrochemical analyses, i.e., cyclic voltammetry, chronoamperometry and electrochemical impedance spectroscopy. All catalysts have onset potential values around $-1.1 \mathrm{~V}$ vs SCE and similar Tafel slopes ( $c a .120 \mathrm{mV} \mathrm{dec}^{-1}$ ) corresponding to the Volmer reaction as the rate determining step of the reaction. These catalysts show an increase of up to $115 \%$ (for $\mathrm{Ni} \mid \mathrm{WO}_{3}$ ) of hydrogen production current compared to conventional Ni catalysts; in most cases preserving great chemical and structural stability after short ageing under alkaline conditions. The composite catalysts were synthesized on low-cost nickel-plated stainless-steel supports, which make them excellent alternatives for replacing massive nickel electrodes in conventional alkaline electrolyzers.
\end{abstract}

\section{Introduction}

The development of highly-active electrocatalysts for hydrogen evolution has gained great attention as a way to tackle the global energy crisis. The generation of $\mathrm{H}_{2}$ through electrocatalytic water splitting is a clean method to generate a fuel source with zero greenhouse gas (GHG) emissions. ${ }^{1}$ To avoid undesirable side reactions from electrochemically-active electrolytes, the process is usually carried out under either extremely acidic conditions - with anodically inert anions- or highly alkaline conditions - using $\mathrm{NaOH}$ or $\mathrm{KOH}$. State-of-the-art electrodes, frequently based on platinum group metals, perform efficiently in highly-acidic working conditions. However, this process, which is often coupled with proton exchange membranes, is considerably expensive; thus, hampering cost-effective industrial applications. ${ }^{2,3}$ On the other hand, alkaline electrolyzers can avoid operation under extremely-corrosive conditions (strong acids) and allow the use

\footnotetext{
a. INFIQC-CONICET, Departamento de Fisicoquímica - Facultad de Ciencias Químicas, Universidad Nacional de Córdoba, Ciudad Universitaria, 5000 Córdoba, Argentina

b. Department of Chemistry and Biomolecular Sciences, Centre for Advanced Materials Research (CAMaR), University of Ottawa, 10 Marie Curie, Ottawa, K1N 6N5, Canada.

*Corresponding authors: anabel.lanterna@icloud.com (AEL)

esteban.franceschini@mi.unc.edu.ar (EAF)

Electronic Supplementary Information (ESI) available: Additional surface and electrochemical characterization included in ESI]. See DOI: 10.1039/x0xx00000x
}

of electrodes based on earth-abundant transition metals reducing the cost of the process and facilitating scalability. ${ }^{4-6}$ The main challenge of these systems is the slow hydrogen kinetics under alkaline conditions. Among the identified parameters that control the hydrogen evolution reaction (HER) activity of the system, we can highlight the nature of the proton donor $\left(\mathrm{H}_{2} \mathrm{O}\right.$ versus $\left.\mathrm{H}_{3} \mathrm{O}^{+}\right)$, the energy necessary for the formation of the activated species on the catalyst surface $\left(\mathrm{H}_{\mathrm{ad}}\right)$ and the availability of catalytic sites. Several studies suggest the HER under alkaline conditions involves a first step - the Volmer step $\left(\mathrm{H}_{2} \mathrm{O}+\mathrm{e}^{-} \rightarrow \mathrm{H}_{\mathrm{ad}}+\mathrm{HO}^{-}\right)-$where $\mathrm{HO}^{-}$and $\mathrm{H}$ species are expected to be adsorbed on the catalyst surface; followed by either the Tafel step $\left(\mathrm{H}_{\mathrm{ad}}+\mathrm{H}_{\mathrm{ad}} \rightarrow \mathrm{H}_{2}\right)$ or Heyrovsky step $\left(\mathrm{H}_{\mathrm{ad}}+\right.$ $\left.\mathrm{H}_{2} \mathrm{O} \rightarrow \mathrm{H}_{2}+\mathrm{HO}^{-}\right) .{ }^{7,8}$ The mechanistic challenge in alkaline media is usually related to the difficulty of breaking the strong covalent $\mathrm{H}-\mathrm{OH}$ bond before adsorbing $\mathrm{H}$ on the surface $\left(\mathrm{H}_{\mathrm{ad}}\right)$. Therefore, when designing new materials for electrocatalytic applications we aim for electrodes with low overpotential and high durability, ensuring fast water dissociation and efficient recombination of $\mathrm{H}_{\mathrm{ad}}$ for large-scale alkaline water splitting. ${ }^{9,} 10$ Nowadays, conventional alkaline electrolyzers are based on bare nickel electrodes, however, they usually have low catalytic activity and high activity-loss rate ${ }^{11}, 12$ hampering the wide application of the technology. Furthermore, most of the highlyactive materials are obtained using complicated methods of synthesis that are expensive and difficult to scale up. ${ }^{13}$ Nevertheless, in recent years, nickel-based composite 
electrodes have attracted attention since they can present a synergistic effect between the materials. ${ }^{14-16}$ It has been reported that $\mathrm{Ni} / \mathrm{TiO}_{2}$ composites substantially improve the electrocatalytic activity towards the HER due to the formation of heterojunctions that affect the Fermi level of nickel..$^{8,17-19}$ Additionally, we have recently shown the potential of niobiumbased semiconductors, particularly $\mathrm{Nb}_{2} \mathrm{O}_{5}$ and $\mathrm{Nb}_{3}\left(\mathrm{PO}_{4}\right)_{5}$, to enhance the electrocatalytic generation of hydrogen ${ }^{20}$ using nickel electrodes in carbonate electrolyte. We found that inclusion of $\mathrm{Nb}_{2} \mathrm{O}_{5}$ to nickel plates can enhance HER efficiency up to values two orders of magnitude higher than those found with conventional $\mathrm{P} 25 \mathrm{TiO}_{2}$ nanoparticles. Further, we have also proposed to reduce the cost of electrodes by replacing conventional nickel electrodes by stainless steel AISI 316L - an inexpensive and stable material suitable for uses under alkaline conditions. We utilized a simple and inexpensive method to deposit nickel and nickel alloys onto stainless steel plates that can be used as electrocatalysts for HER;21, 22 a method that can be also used to prepare electrodes based on nickelsemiconductor composites. ${ }^{17}$ Here, we explored the use of this binder-free method to synthesize nickel-semiconductor composite (denoted as $\mathrm{Ni} \mid \mathrm{SC}$ ) electrodes using four different $\mathrm{SC}$ $\left(\mathrm{Nb}_{2} \mathrm{O}_{5}, \mathrm{Nb}_{3}\left(\mathrm{PO}_{4}\right)_{5}, \mathrm{Bi}_{2} \mathrm{O}_{3}\right.$ and $\left.\mathrm{WO}_{3}\right)$ and evaluate their effect on the HER activity of Ni-based electrodes. These semiconductors have previously been explored as photocatalysts ${ }^{23-29}$ and shown potential capacity for hydrogen generation. Particularly for $\mathrm{Bi}_{2} \mathrm{O}_{3}$ and $\mathrm{WO}_{3}$, it has been suggested that the metal centres can behave as microcathodes, which can show a potential effect on nickel cathodes commonly used in conventional alkaline electrolyzers. Moreover, recent studies demonstrated that $\mathrm{Ni} \mid \mathrm{Bi}_{2} \mathrm{O}_{3}$ composites exhibit higher microhardness than conventional nickel deposits, ${ }^{30}$ making the composite a suitable candidate for engineering uses. It was also found that $\mathrm{WO}_{3}$ can improve the corrosion resistance and increase the catalytic activity of Ni-P catalysts. ${ }^{31}$ These are great advantages for exhausting situations such as the generation of hydrogen under alkaline conditions.

We present here the study of a series of different semiconductors for the synthesis of $\mathrm{Ni} / \mathrm{SC}$ electrodes that enhance the electrocatalytic properties of $\mathrm{Ni}$ electrodes whilst improving their stability. The $\mathrm{Ni} \mid \mathrm{SC}$ electrodes are synthesized through a simple, binder-free method that can be easily scaled up for industrial production of large-area electrodes for both conventional and zero-gap alkaline electrolyzers. We found that the electrocatalytic activity of synthesized $\mathrm{Ni}$ /SC electrodes towards HER in alkaline solutions is highly enhanced by the incorporation of SC particles in the nickel matrix. This method constitutes a promising strategy for tuning the electrocatalytic properties of $\mathrm{Ni}$-based electrodes, particularly for HER.

\section{Experimental}

Nickel chloride hexahydrate (Merck, PA grade), nickel sulfate hexahydrate (Anedra, PA grade), boric acid (Merck, PA grade), hydrochloric acid (36.5\%-37\%, Cicarelli, PA grade), ethanol (96\%, Cicarelli, PA grade), potassium hydroxide (Anedra RA reagent), $\mathrm{Nb}_{2} \mathrm{O}_{5}$ (CBMM, Companhia Brasileira de Metalurgia e
Mineracao -CBMM-), $\mathrm{WO}_{3}\left(99,9 \%\right.$, puriss, powder) $\mathrm{N}_{w} \mathrm{Nb}_{3}\left(\mathrm{PO}_{4}\right)_{5}$ (CBMM), $\mathrm{Bi}_{2} \mathrm{O}_{3}$ (99.9\%, Reagent Plus ${ }^{\circledR}$, poviderip received. All solutions were prepared with deionized water. Stainless steel AISI 316L (denoted as SS316L) plates with dimensions of $20 \times 35 \times 2.5 \mathrm{~mm}$ were used as substrates. Each SS316L plate was covered with insulating tape leaving a $4-\mathrm{cm}^{2}$ exposed area $\left(2 \times 2 \mathrm{~cm}^{2}\right)$. The composition of the SS316L was: $\mathrm{Cr}$ $17 \%$, Ni $12 \%$, C $0.01 \%$, Mn 2\%, Si $0.75 \%$, P 0.045\%, S 0.03\%, Mo $2.50 \%, \mathrm{Fe} \%$ Bal.

The preparation of the electrodes was performed using two different electrodeposition baths, the nickel strike and the nickel Watts baths, which were prepared as follows:

Nickel strike bath. The Ni strike-plating layer is used to activate the surface of the steel plates for improved adhesion of the $\mathrm{Ni}$ and $\mathrm{Ni}$ |SC catalysts. The bath was composed by $225 \mathrm{~g} / \mathrm{L} \mathrm{NiCl}_{2}$ solution at $\mathrm{pH} 0.5(\mathrm{HCl}(38 \% \mathrm{~V} / \mathrm{V})$ was used to reach the desired $\mathrm{pH})$.

Nickel Watts bath. The Ni|SC electrodes were synthesized by electrodeposition using a conventional Watts nickel bath ${ }^{17,21}$ modified by the addition of the corresponding $\mathrm{SC}$ particles. The bath was composed by $\mathrm{NiSO}_{4} \bullet 6 \mathrm{H}_{2} \mathrm{O} 280 \mathrm{~g} / \mathrm{L}, \mathrm{NiCl}_{2} \bullet 6 \mathrm{H}_{2} \mathrm{O} 35 \mathrm{~g} / \mathrm{L}$, boric acid $45 \mathrm{~g} / \mathrm{L}$ and $3 \mathrm{~g} / \mathrm{L}$ of the corresponding SC particles.

The preparation of the $\mathrm{Ni} \mid \mathrm{SC}$ electrodes was performed using the following methodology. In order to prepare the SS316L surface for the electrodeposition process and increase their electrochemical stability, the plates were pre-treated following a reported method. ${ }^{21,} 22$ Briefly, the plates were mechanically polished with \#600 sandpaper for $6 \mathrm{~min}$, sonicated for $30 \mathrm{~min}$ in acetone and rinsed with ethanol and MilliQ water. Then, the plates were immersed for $15 \mathrm{~min}$ in $1.0 \mathrm{M} \mathrm{KOH}$ aqueous solution at $323 \mathrm{~K}$. After that, they were subjected to an anodic current pulse of $1 \mathrm{mAcm}^{-2}$ during $15 \mathrm{~min}$ in a $1.0 \mathrm{M}$ nitric acid solution. This promotes the oxidation of any organic traces that might be present on the support's surface. Finally, 1-minute successive immersions of the plates in $1.0 \mathrm{M} \mathrm{KOH}, 13.2 \mathrm{w} / \mathrm{v} \% \mathrm{HCl}$ and 5 $\mathrm{w} / \mathrm{v} \% \mathrm{H}_{2} \mathrm{SO}_{4}$ were carried out to completely eliminate oxides and activate the surface, providing an oxide-free surface which ensures good $\mathrm{Ni}$ adhesion and synthesis reproducibility. ${ }^{21}$ Once the SS316L surface is ready, a nickel adherence layer was electrodeposited using a nickel strike electrodeposition bath by application of a $-0.05 \mathrm{Acm}^{-2}$ pulse at $328 \mathrm{~K}$ during $1800 \mathrm{s.}^{21,22}$ Finally, the $\mathrm{Ni} \mid \mathrm{SC}$ electrodeposition was performed in a two electrodes cell with a nickel anode, by application of a -0.05 $\mathrm{Acm}^{-2}$ pulse at $328 \mathrm{~K}$ during $2700 \mathrm{s.}^{32}, 33$ The same protocol, in the absence of SC particles, was used to synthesize electrodes (Ni|Watts) for control experiments.

Structural characterization was performed using the following equipment. SEM micrographs were obtained using a Supra 40 FESEM (Zeiss Company) operating at $3 \mathrm{kV}$ equipped with EDS (Oxford). The X-ray diffractograms were obtained using the $\lambda=$ $1.5406 \AA \mathrm{Cu} \mathrm{K} \alpha$ radiation, with a PANalytical X'Pert PRO diffractometer operating at $40 \mathrm{kV}$ and $40 \mathrm{~mA}$, in the $\theta-2 \theta$ BraggBrentano geometry. The $2 \theta$ range used was between $10^{\circ}$ and $70^{\circ}$, with $0.02^{\circ}$ steps and counting time of $2 \mathrm{~s}$ per step at room temperature. Raman spectra were acquired with a LABRAM-HR, Horiba Jobin-Yvon Raman microscope with a 100x objective lens (NA $=0.9)$. The illuminated area in all Raman experiments was 
$1.0 \mu^{2}$ using a $632.8 \mathrm{~nm}$ laser $(3.5 \mathrm{~mW})$ with a spectral resolution of $1.5 \mathrm{~cm}^{-1}$. Confocal micrographs obtained using an Olympus LEXT OLS4000 employing a $405 \mathrm{~nm}$ wavelength laser, magnifications of $\times 2132$, with a pitch in the z-axis of $0.01 \mu \mathrm{m}$ with area for data collection of $130 \times 130 \mu \mathrm{m}$. XPS spectra were measured on a Kratos Axis Nova spectrometer equipped with an Al X-ray source. The stainless-steel plates were mounted onto the coated aluminium platen using two stripes (top and bottom) of double-sided adhesive $\mathrm{Cu}$ tape. All samples were kept under high vacuum $\left(10^{-9}\right.$ Torr $)$ overnight inside the preparation chamber before they were transferred into the analysis chamber (ultrahigh vacuum, $10^{-10}$ Torr) of the spectrometer. The XPS data were collected using Al K $\alpha$ radiation at $1486.69 \mathrm{eV}(150 \mathrm{~W}, 10 \mathrm{~mA})$, charge neutralizer and a delayline detector (DLD) consisting of three multi-channel plates. Binding energies are referred to the $\mathrm{C} 1 \mathrm{~s}$ peak at $285 \mathrm{eV}$. Survey spectra were recorded from -5 to $1200 \mathrm{eV}$ at a pass energy of $160 \mathrm{eV}$ (number of sweeps: 2) using an energy step size of $1 \mathrm{eV}$ and a dwell time of $100 \mathrm{~ms}$. High resolution spectra for $\mathrm{Ni2p}$ and $\mathrm{Ni}$ (Auger) were recorded in the appropriate regions at a pass energy of $20 \mathrm{eV}$ (number of sweeps/dwell time: Ni2p, 10/200 $\mathrm{ms}$; Ni(Auger), 10/200 ms) using an energy step size of $0.1 \mathrm{eV}$. The analyzed area on the specimens was about $300 \times 700 \mu \mathrm{m}^{2}$. The incident angle (X-ray source/sample) is the magic angle of $54.74^{\circ}$ and the take-off angle (sample/detector) is $90^{\circ}$.

Electrochemical characterization was performed in a threeelectrode electrochemical cell using $1.0 \mathrm{M} \mathrm{KOH}$ aqueous solution as electrolyte. A large-area platinum foil was used as counter electrode and a saturated calomel electrode (SCE) as reference electrode $(0.243 \mathrm{~V}$ vs. RHE). The electrochemical experiments were carried out employing a Parstat 2273 potentiostat/galvanostat. All current densities (j) were calculated based on a 4-cm² electrode area. Cyclic voltammetry (CV) experiments were carried out between 0.1 and $-1.5 \mathrm{~V}$ (vs SCE) at a scanning rate of $10 \mathrm{mVs}^{-1}$ at $298 \mathrm{~K}$. Electrochemical impedance spectroscopy (EIS) experiments were performed at frequencies between $10 \mathrm{mHz}$ and $100 \mathrm{kHz}$ using a $10 \mathrm{mV}$ bias potential at different electrode potentials (open circuit potential (OCP), -1.1, -1.2 and $-1.4 \mathrm{~V}$ vs SCE). ZView 3.3 software (Scribner Associates, Inc.) was used to fit the measured data with different equivalent circuit models. Electrodes short ageing process was performed by chronoamperometry. The profiles were measured by applying a potential pulse of $-1.5 \mathrm{~V}$ (Vs. SCE) during $4 \mathrm{~h}$ at $298 \mathrm{~K}$ in $1.0 \mathrm{M} \mathrm{KOH}$ aqueous solution.

\section{Results and discussion}

The Ni|SC electrodes were prepared by electrodeposition of $\mathrm{Ni}$ in the presence of the corresponding $\mathrm{SC}$ (i.e., $\mathrm{Nb}_{2} \mathrm{O}_{5}, \mathrm{Nb}_{3}\left(\mathrm{PO}_{4}\right)_{5}$, $\mathrm{Bi}_{2} \mathrm{O}_{3}$ or $\mathrm{WO}_{3}$ ) particles. Analysis of SEM images (Figure 1) for each electrode, shows the $\mathrm{Ni}$ /SC electrodes composed by $\mathrm{Nb}_{2} \mathrm{O}_{5}$ or $\mathrm{WO}_{3}$ present a cauliflower-like structure, while those containing $\mathrm{Nb}_{3}\left(\mathrm{PO}_{4}\right)_{5}$ or $\mathrm{Bi}_{2} \mathrm{O}_{3}$ seem to preserve the smooth surface found in conventional nickel Watts catalysts (denoted as Ni |Watts). ${ }^{32}$ Additionally, the relative elemental composition of the electrodes was determined by EDS. Although the absolute Ni-SC composition cannot be determined under these conditions, the molar ratio between $\mathrm{Ni}$ and the metal centres allows us to infer the relative amount ofDSt aldedediplifferefent samples (Table 1). Similar molar amounts of SC are found for all $\mathrm{SC}$ except for $\mathrm{Nb}_{3}\left(\mathrm{PO}_{4}\right)_{5}$. Different $\mathrm{SC}$ loadings can be expected due to the different particle size of the SC - and possibly, also due to their chemical nature - which can control the electrodeposition process. ${ }^{33,}{ }^{34}$ In order to further explore the distribution of the SC particles on the electrode surface, we have completed the chemical composition mapping of the electrode surface by EDS. Figures S1 to S4 show the formation of $\mathrm{SC}$ aggregates on the nickel deposit surface. It is important to note that $\mathrm{O}$ content on the electrode is confined to the SC aggregates, suggesting that the $\mathrm{Ni}$ coating is metallic $\mathrm{Ni}$. In addition, confocal microscopy images (Figure S5) allow to estimate the macroscopic area of the electrodes and calculate their roughness factor $\left(R_{f}\right)$, Table S2. We found 1.24, 1.38, 1.77 and $1.84 \mathrm{R}_{\mathrm{f}}$ values for $\mathrm{Ni}\left|\mathrm{Nb}_{3}\left(\mathrm{PO}_{4}\right)_{5}, \mathrm{Ni}\right| \mathrm{Bi}_{2} \mathrm{O}_{3}, \mathrm{Ni} \mid \mathrm{WO}_{3}$, and $\mathrm{Ni} \mid \mathrm{Nb}_{2} \mathrm{O}_{5}$, respectively. Slightly high values of surface roughness can be related to those catalysts showing cauliflower-like structure.

Table 1. Elemental composition of the Ni|SC obtained by EDS.

\begin{tabular}{ccc}
\hline $\mathrm{Ni} \mid \mathrm{SC}$ & $\mathrm{Ni}$ & $\mathrm{X}$ \\
\hline $\mathrm{Ni} \mid \mathrm{Nb}_{2} \mathrm{O}_{5}$ & 87.9 & $12.5(1)$ \\
$\mathrm{Ni} \mid \mathrm{Nb}_{3}\left(\mathrm{PO}_{4}\right)_{5}$ & 97.7 & $2.3(0.12)$ \\
$\mathrm{Ni}_{\mathrm{Bi}} \mathrm{O}_{3}$ & 90.1 & $9.9(0.79)$ \\
$\mathrm{Ni} \mid \mathrm{WO}_{3}$ & 95.2 & $4.8(0.77)$ \\
\hline
\end{tabular}

$X$ corresponds to the amount of metal from the different $\mathrm{SC}$ ( $\mathrm{Nb}$ for $\mathrm{Nb}_{2} \mathrm{O}_{5}$ and $\mathrm{Nb}_{3}\left(\mathrm{PO}_{4}\right)_{5}, \mathrm{Bi}$ for $\mathrm{Bi}_{2} \mathrm{O}_{3}$ and $\mathrm{W}$ for $\left.\mathrm{WO}_{3}\right)$. Values between brackets: $\mathrm{SC}$ molar ratio between samples relative to $\mathrm{Ni} \mid \mathrm{Nb}_{2} \mathrm{O}_{5}$.

The crystalline structure characterization of the electrodes (Figure 2) suggests the presence of a face-centred cubic (fcc) structure for $\mathrm{Ni}^{35}$ The $2 \theta$ typical values for the $\mathrm{Ni}(111)$ and (200) planes are $44.3^{\circ}$ and $51.7^{\circ}$, respectively. The Ni|SC cell parameters and average crystal size were calculated using Scherrer's equation ${ }^{33,} 36$ (Table 2). The incorporation of the semiconductor nanoparticles slightly changes the crystallite size, being the (200) plane the most susceptible to the presence of the oxide particle - particularly in the case of $\mathrm{Nb}_{2} \mathrm{O}_{5}$ and $\mathrm{WO}_{3}$. On the other hand, the position of the diffraction peaks, the dspacing distance and the FWHM remain virtually unchanged upon addition of different SC (Table 2). In addition, the diffraction peaks corresponding to the semiconductor oxides are observed ( $c f$. Figure S6), indicating that the semiconductor nanoparticles maintain their crystalline structure after incorporation into the composite material.

Analysis of Figure 2, indicates that the ratio of intensities of (111) peak to (200) peak is below one - i.e., $\operatorname{peak}_{(111)} /$ peak $_{(200)}$ $<1$ - for the $\mathrm{Ni} \mid \mathrm{Bi}_{2} \mathrm{O}_{3}$ and $\mathrm{Ni} \mid \mathrm{Nb}_{3}\left(\mathrm{PO}_{4}\right)_{5}$ electrodes. This relation is also found in the Ni|Watts electrode (in the absence of SC particles) and it is in agreement with the similarities found on the surface morphologies observed in the SEM images (Figure 1). In contrast, both $\mathrm{Ni} \mid \mathrm{WO}_{3}$ and $\mathrm{Ni} \mid \mathrm{Nb}_{2} \mathrm{O}_{5}$ electrodes present the ratio $\operatorname{peak}_{(111)} / \operatorname{peak}_{(200)}>1$, which is similar to that found 
for other hybrid nickel electrocatalysts, ${ }^{37}$ and coincides with the catalysts showing the cauliflower-like structure seen by SEM. The structural differences found are important evidence of how the nature of the semiconductor can cause changes in the structure of the final composite; although the SC crystalline structures remain unchanged after electrodeposition (Table S2).

Moreover, the chemical composition of the Ni|SC electrodes was evaluated by Raman spectroscopy (Figure 3). The scattering spectra from the conventional $\mathrm{Ni}$ Watts electrode show no peaks, indicating that the nickel is in the metallic state in agreement with our EDS analysis (vide supra). ${ }^{16,38,39}$ The Ni|SC electrodes show the characteristic peaks of the semiconductor nanoparticles, $40-42$ confirming that the semiconductors maintain their chemical structure after incorporation into the $\mathrm{Ni} \mid \mathrm{SC}$ electrode as we predicted from the crystalline structural analysis. Spectra acquired in the areas where the nanoparticles aggregates are not observed show no Raman signals, as expected for metallic nickel.

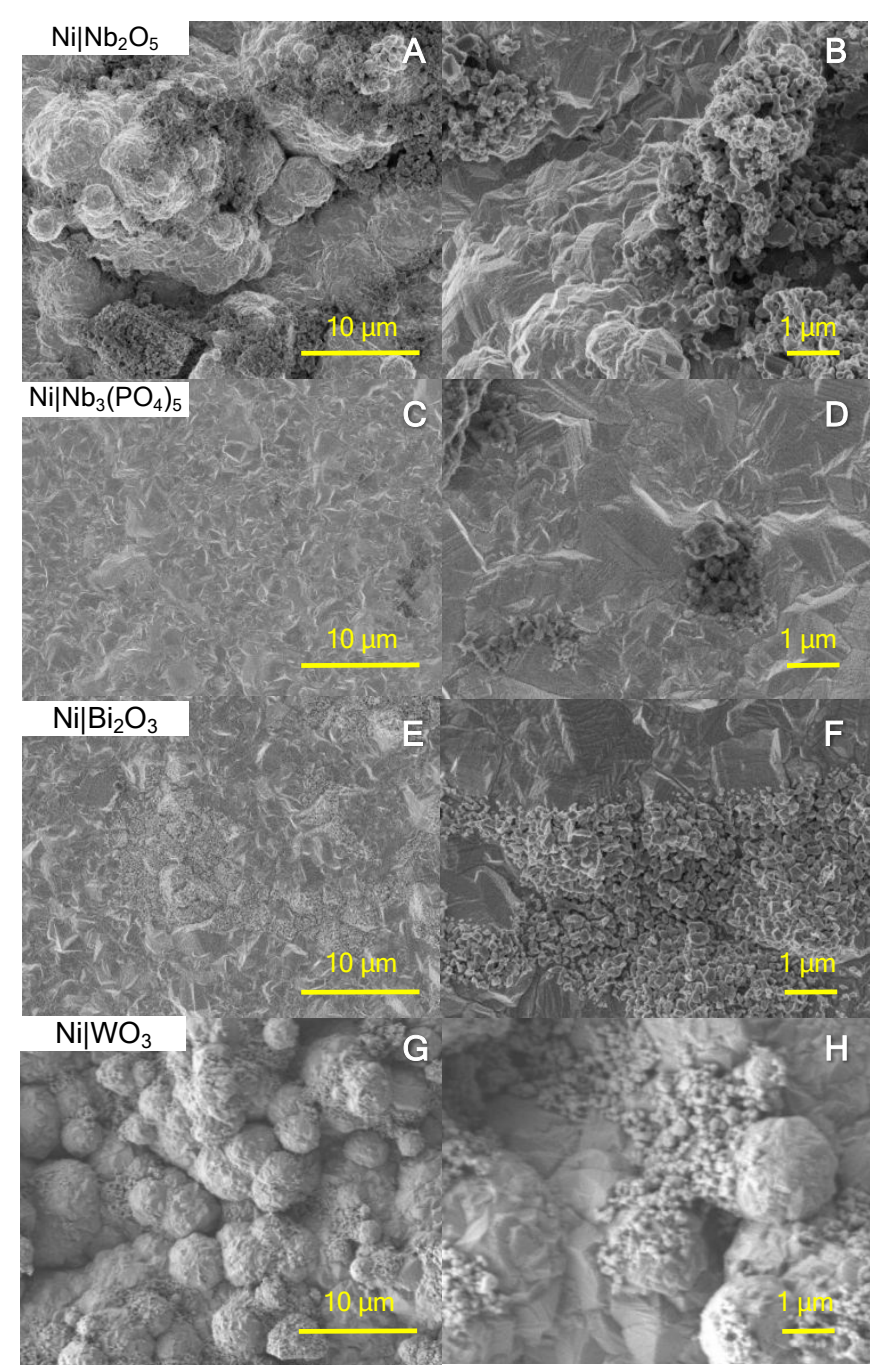

Figure 1. SEM images (at two different magnifications) for all Ni|SC electrodes synthesized.
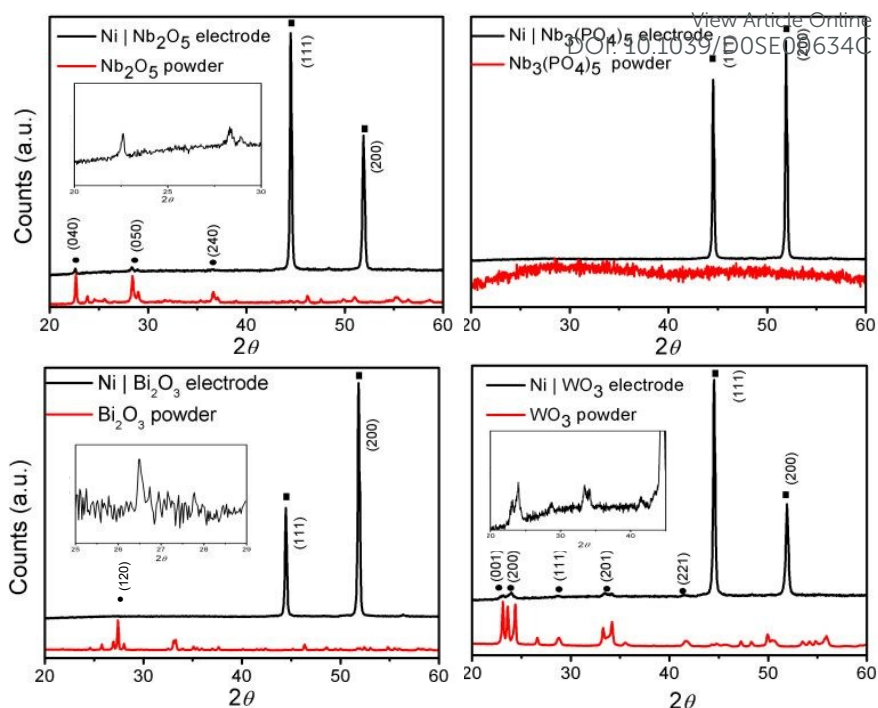

Figure 2. X-ray diffraction (XRD) pattern of $\mathrm{Ni} \mid \mathrm{SC}$ electrodes (black) and pure SC (red).

Table 2. XRD parameters calculated for the Ni|SC catalysts

\begin{tabular}{llllll}
\hline $\mathrm{Ni} \mid \mathrm{SC}$ & $2 \theta\left(^{\circ}\right)$ & $\begin{array}{l}\text { FWHM } \\
\left({ }^{\circ}\right)\end{array}$ & $\begin{array}{l}\text { Crystallite } \\
\text { size }(\mathrm{nm})\end{array}$ & $\mathrm{d}(\AA)$ & Plane \\
\hline Watts $^{21}$ & 44.3 & 0.265 & 33.8 & 2.04 & $(111)$ \\
& 51.7 & 0.295 & 31.2 & 1.77 & $(200)$ \\
$\mathrm{Nb}_{2} \mathrm{O}_{5}$ & 44.5 & 0.21 & 42.7 & 2.03 & $(111)$ \\
$\mathrm{Nb}_{3}\left(\mathrm{PO}_{4}\right)_{5}$ & 51.9 & 0.27 & 34.2 & 1.76 & $(200)$ \\
$\mathrm{Bi}_{2} \mathrm{O}_{3}$ & 51.9 & 0.20 & 44.8 & 2.03 & $(111)$ \\
$\mathrm{WO}_{3}$ & 44.4 & 0.22 & 41.9 & 1.76 & $(200)$ \\
\hline
\end{tabular}
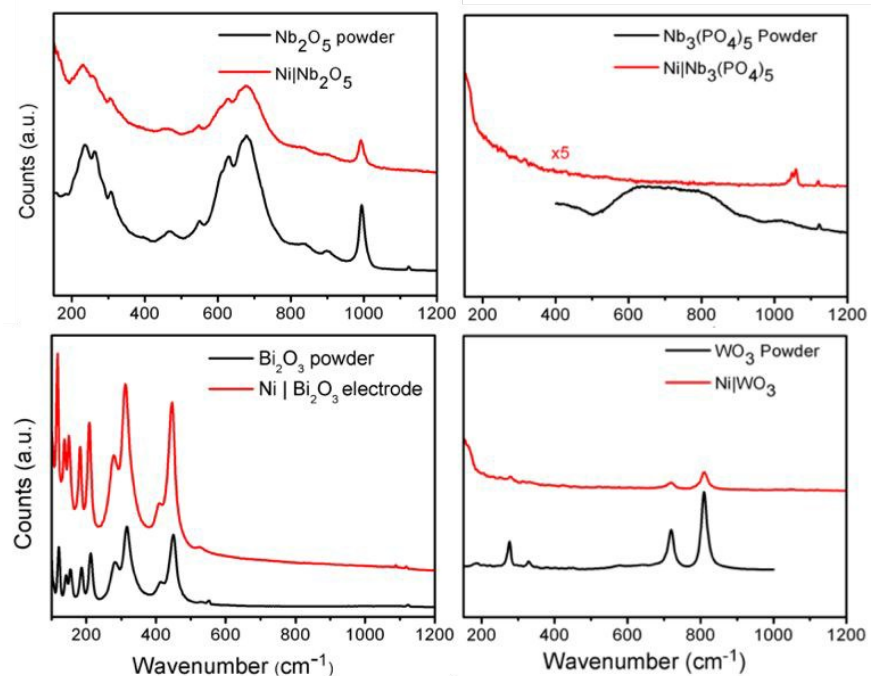

Figure 3. Raman spectra of $\mathrm{Ni} \mid \mathrm{SC}$ electrodes (red) and pure SC (black).

X-ray photoelectron spectroscopy (XPS) measurements are very useful to analyze $\mathrm{Ni}$ species on the surface of the Ni|SC electrodes. The analysis of the Ni $2 p$ HR XPS spectra (Figure S7) show the presence of the $\mathrm{Ni} 2 \mathrm{p}_{1 / 2}$ and $\mathrm{Ni} 2 \mathrm{p}_{3 / 2}$ two spin-orbit 
signals corresponding to metallic Ni species and appears to be in agreement with the peaks found in Figure $\mathrm{S} 8$ showing the $\mathrm{Ni}$ LMM Auger spectra (Table S2). There is no evidence of the presence of $\mathrm{Ni}(\mathrm{OH})_{2}$ species $^{43}$ and although, superficial $\mathrm{NiO}$ species cannot be ruled out through this technique, we were able to confirm only the presence of metallic nickel by XRD and Raman spectroscopy. Additionally, HR XPS spectra - centred at $\mathrm{Nb} 3 \mathrm{~d}, \mathrm{Bi} 4 \mathrm{f}$ and $\mathrm{W} 4 \mathrm{f}$ regions for each catalyst respectively suggest more reduced SC species are present on the surface of the electrodes (Figure S9). It is important to note that XPS analysis can only explore the outermost layer of the specimen, ${ }^{44}$ and that XRD analysis - with higher penetration depth - give a better understanding of the overall composition of the electrodes.

The electrocatalytic activity for HER was evaluated by cyclic voltammetry (CV) and the stability of the electrodes assessed by chronoamperometry. For Ni-based electrodes, the formation/reduction of surface oxides close to the onset potential $(O P)^{38}$ makes the determination of these values very challenging. For this reason, the catalytic activity of the different electrodes was evaluated by direct comparison of their current densities (j) at a known voltage (e.g., $-1.5 \vee$ vs SCE). Given the well-known difficulties in determining the electrochemically active surface area of $\mathrm{Ni}$-based electrodes, ${ }^{45}$ we resort to comparing electrodes efficiencies based on the electrodes geometric area. The $j$ value is related to the exchange current $\left(\mathrm{j}_{0}\right)$ and the OP values and is directly proportional to the rate of current change $(d j / d V)$. Particularly, for the same OP values, a catalyst with higher $\mathrm{dj} / \mathrm{dV}$ will present higher current density for HER and, therefore, a greater catalytic activity. ${ }^{46}$ In Figure 4, all $\mathrm{Ni} \mid \mathrm{SC}$ electrodes seem to have OP values close to $-1.1 \mathrm{~V}$ (vs $\mathrm{SCE}$ ), which is consistent with the OP value estimated in literature for bare nickel. ${ }^{47,}{ }^{48}$ Remarkably, we can note an increment in the hydrogen evolution current at $-1.5 \mathrm{~V}$ (vs. SCE) by incorporating $\mathrm{Bi}_{2} \mathrm{O}_{3}$ or $\mathrm{WO}_{3}$ into the $\mathrm{Ni}$ electrocatalyst structure. In these cases, we found values of $\mathrm{j}$ of about 1.5 times higher than the one measured with $\mathrm{Ni}$ |Watts catalyst. This enhanced catalytic activity could be related to changes in dynamics of the electrochemical process (vide infra). Additionally, oxidation/reduction peaks of catalytic species are observed around the OP (Figure S10). These peaks are normally associated with the formation of oxidized species on the electrode surface and its subsequent reduction. It has been reported in literature, that in the case of pure nickel these peaks correspond to species of $\mathrm{Ni}(\mathrm{OH})_{2}$ and $\mathrm{NiO}_{x}$ only, ${ }^{46,} 49$ while in composite electrodes, we also expect peaks for the redox activity of the SC. ${ }^{46}$

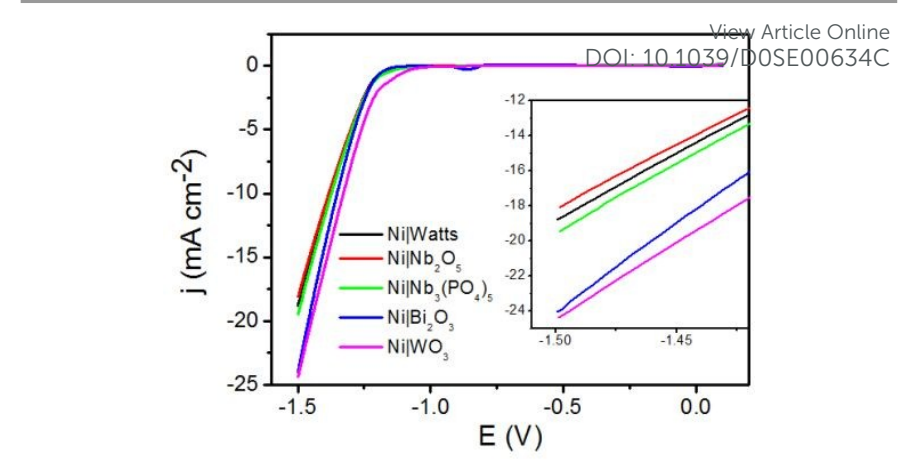

Figure 4. Cyclic voltammogram of $\mathrm{Ni} \mid$ Watts, and the $\mathrm{Ni} \mid \mathrm{SC}$ electrodes measured at 10 $\mathrm{mVs}^{-1}$ and $298 \mathrm{~K}$. Current density $(j)$ calculated based on the electrode geometric area.

In order to understand the HER, electrochemistry and kinetics of the process using $\mathrm{Ni} / \mathrm{SC}$ electrodes were studied using Tafel analysis (Figure S11 and Table 3). In all cases, calculated Tafel slope values are ca. $120 \mathrm{mV} \mathrm{dec}^{-1}$, similar to the value found in conventional $\mathrm{Ni}$ electrodes. ${ }^{35}, 50,51$ These values are in agreement with the Volmer reaction being the rate determining step of the global HER (i.e., Tafel slopes found corresponds to the first electron transfer, with a theoretical Tafel slope of 120 $\left.\mathrm{mV} \mathrm{dec}^{-1}\right)$. It was observed that the equilibrium potential $\left(\mathrm{E}_{\mathrm{eq}}\right)$ for the $\mathrm{Ni} \mid \mathrm{Bi}_{2} \mathrm{O}_{3}$ and $\mathrm{Ni} \mid \mathrm{Nb}_{3}\left(\mathrm{PO}_{4}\right)_{5}$ catalysts is similar to that found in conventional $\mathrm{Ni}$ /Watts, while we found a diminution of approximately $100 \mathrm{mV}$ in the $\mathrm{E}_{\text {eq }}$ values for $\mathrm{Ni} \mid \mathrm{Nb}_{2} \mathrm{O}_{5}$ and $\mathrm{Ni} \mid \mathrm{WO}_{3}$ catalysts. Additionally, the exchange current $\left(\mathrm{j}_{0}\right)$ for $\mathrm{Ni} \mid \mathrm{Nb}_{2} \mathrm{O}_{5}$ is almost 75 times greater than for Ni/Watts, indicating that this catalyst should have a superior catalytic activity in the chronoamperometric experiments (vide infra). ${ }^{52}$ Furthermore, we studied the stability of electrodes by chronoamperometry, i.e., 4-hour exposure of the electrodes to the HER conditions. As shown in Figure $5, \mathrm{Ni} \mid \mathrm{Nb}_{2} \mathrm{O}_{5}$ and $\mathrm{Ni} \mid \mathrm{WO}_{3}$ electrodes have a superior $\mathrm{HER}$ catalytic activity compared to their $\mathrm{Ni} /$ Watts, $\mathrm{Ni} / \mathrm{Nb}_{3}\left(\mathrm{PO}_{4}\right)_{5}$ and $\mathrm{Ni} \mid \mathrm{Bi}_{2} \mathrm{O}_{3}$ counterparts. Notably, all catalysts show great electrochemical stability, probably due to the reductive conditions that prevent the oxidation of the Ni surface. Based on the chronoamperometric analysis, we could calculate the electrode deactivation rate $(\delta)$ based on the following equation $32,53,54$ :

$$
\delta=-\frac{100}{j_{e}}(d j / d t)
$$

where $j_{\mathrm{e}}$ is the current extrapolated at the starting point of the chronoamperometric profile, and the slope, $(d j / d t)$, is evaluated from the linear decay at $t>4000 \mathrm{~s}$. The results summarized in Table 3 show that all $\mathrm{Ni} \mid \mathrm{SC}$ electrodes present lower deactivation rates comparing to the $\delta$ value found for conventional $\mathrm{Ni} /$ Watts electrode. Among the different $\mathrm{SC}$ evaluated, $\mathrm{Nb}_{2} \mathrm{O}_{5}$ and $\mathrm{Nb}_{3}\left(\mathrm{PO}_{4}\right)_{5}$ show the smallest deactivation rates.

Additionally, we calculated the increase in the total current density by performing CV experiments with the electrodes after the short ageing process (Figure S12) and comparing the results to the $\mathrm{CV}$ recorded for fresh $\mathrm{Ni} \mid \mathrm{SC}$ electrodes. The greatest activation after short ageing was observed for electrodes based on $\mathrm{Nb}_{2} \mathrm{O}_{5}$ and $\mathrm{Nb}_{3}\left(\mathrm{PO}_{4}\right)_{5}$ semiconductors, with 67.6 and $60.9 \%$ of activation, respectively. We also determined the rate of 
current change $(d j / d V)$ for fresh and aged catalysts and calculated the activation from these values (table 4). Same activation values as those shown in table 3 indicate no major changes in the OP of the catalysts after short ageing. This activation is usually attributed to two different phenomena: surface stabilization due to reduction of surface oxides ${ }^{46,55}$ and changes in the catalyst surface area. In our case, the presence of unreactive nickel oxide-hydroxide species before and after ageing process are ruled out by both XRD and Raman analysis (Figures 2-3 and S12-S13). These oxygenated species are normally detected by Raman on pure nickel catalysts after this type of short ageing treatment, ${ }^{16}$ however, we found no evidence for the formation of surface nickel hydroxides - their characteristic Raman signals (at 3581 and $3660 \mathrm{~cm}^{-1}$ ) were not observed. ${ }^{56}$

Table 3. Electrochemical and kinetic parameters for HER using the $\mathrm{Ni} \mid \mathrm{SC}$ electrodes in $1.0 \mathrm{M} \mathrm{KOH}$ aqueous solution.

\begin{tabular}{llll}
\hline $\mathrm{Ni} \mid \mathrm{SC}$ & $\mathrm{E}_{\text {eq }}(\mathrm{V}$ vs SCE $)$ & $j_{0}\left(\mu \mathrm{Acm}^{-2}\right)$ & $\mathrm{b}\left(\mathrm{mVdec}^{-1}\right)$ \\
\hline Watts & -0.81 & 2.43 & 116.9 \\
$\mathrm{Nb}_{2} \mathrm{O}_{5}$ & -0.69 & 179 & 121.0 \\
$\mathrm{Nb}_{3}\left(\mathrm{PO}_{4}\right)_{5}$ & -0.79 & 9.63 & 126.2 \\
$\mathrm{Bi}_{2} \mathrm{O}_{3}$ & -0.81 & 2.29 & 128.8 \\
$\mathrm{WO}_{3}$ & -0.70 & 5.88 & 124.7 \\
\hline $\mathrm{Ni} \mid \mathrm{SC}$ & $\delta\left(\times 10^{-3} \mathrm{~s}^{-1}\right)$ & $j(\mathrm{mAcm}-2)$ & Ageing activation (\%) \\
\hline $\mathrm{Watts}$ & 1.50 & -17.6 & 10.5 \\
$\mathrm{Nb}_{2} \mathrm{O}_{5}$ & 0.63 & -18.1 & 67.6 \\
$\mathrm{Nb}_{3}\left(\mathrm{PO}_{4}\right)_{5}$ & 0.24 & -19.4 & 60.9 \\
$\mathrm{Bi}_{2} \mathrm{O}_{3}$ & 1.38 & -24.2 & 7.5 \\
$\mathrm{WO}_{3}$ & 1.19 & -24.3 & 13.2 \\
\hline
\end{tabular}

Equilibrium potential $\left(E_{e q}\right)$, Exchange current density $\left(j_{0}\right)$, Tafel slope (b), Deactivation rate $(\delta)$, Current density at $-1.5 \mathrm{~V}$ vs SC (j) for fresh catalysts and ageing activation.

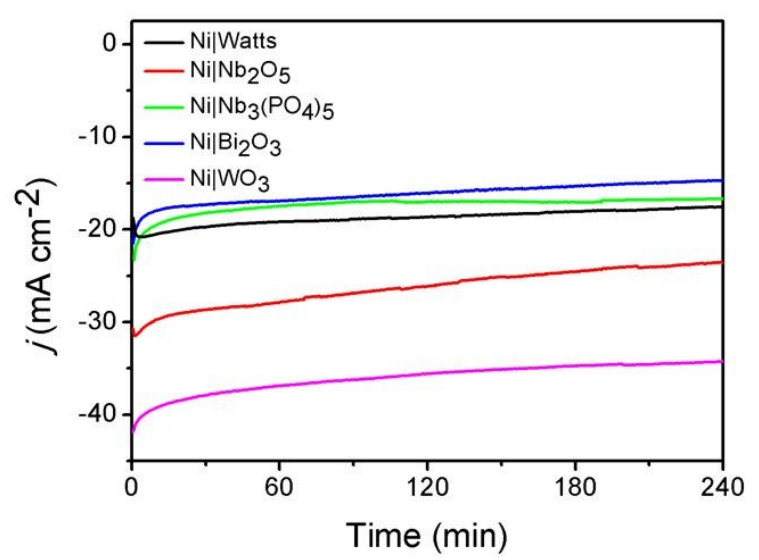

Figure 5. Chronoamperometric profiles for each Ni|SC electrode measured at $-1.5 \mathrm{~V}$ (vs $\mathrm{SCE}$ ) in $1.0 \mathrm{M} \mathrm{KOH}$ aqueous solution at $298 \mathrm{~K}$ for $4 \mathrm{~h}$.

Furthermore, we studied the dynamics of the electrochemical process taking place for each catalyst by EIS. For this, we evaluated the HER activity of the different catalysts in alkaline medium by recording Nyquist plots at various potentialsoand fitting them with the following methods! the 3 armstropfo ${ }^{4} \&$ Henderson equivalent circuit (AHEC) ${ }^{46,57-59}$ - with one constant phase element (CPE) to account for the capacitance dispersion 60-62 caused by the surface roughness of the electrode, ${ }^{63}$ and a modified Randles model (Randles-CPE). ${ }^{58}$ Figure S15 shows the comparison between the different fit of data for the catalyst $\mathrm{Ni} \mid \mathrm{Bi}_{2} \mathrm{O}_{3}$ at $-1.2 \mathrm{~V}$ (vs SCE). An excellent approximation to the experimental data for all catalysts was obtained using the model presented in Figure S15b (AHEC1CPE). Figure 6 shows the experimental measurements and the fit obtained for the different $\mathrm{Ni}$ |SC catalysts together with a conventional $\mathrm{Ni}$ | Watts electrode (See Figure S16 for complete analysis). It is interesting to note that all Ni|SC catalysts have a smaller semicircle diameter than that found with $\mathrm{Ni}$ Watts, according to their higher catalytic activity.

\begin{tabular}{|c|c|c|c|}
\hline \multirow{2}{*}{$\mathrm{Ni} \mid \mathrm{SC}$} & \multicolumn{2}{|c|}{$d j / d V\left(\mu \mathrm{A} \mathrm{cm}{ }^{-2} V^{-1}\right)$} & \multirow{2}{*}{$\begin{array}{l}\text { Ageing } \\
\text { activation (\% }\end{array}$} \\
\hline & Fresh & Aged & \\
\hline Watts & 68.9 & --- & --- \\
\hline $\mathrm{Nb}_{2} \mathrm{O}_{5}$ & 66.2 & 106.4 & 60.7 \\
\hline $\mathrm{Nb}_{3}\left(\mathrm{PO}_{4}\right)_{5}$ & 71.7 & 114.8 & 60.1 \\
\hline $\mathrm{Bi}_{2} \mathrm{O}_{3}$ & 91.5 & 100.8 & 10.2 \\
\hline $\mathrm{WO}_{3}$ & 83.6 & 90.7 & 8.5 \\
\hline
\end{tabular}

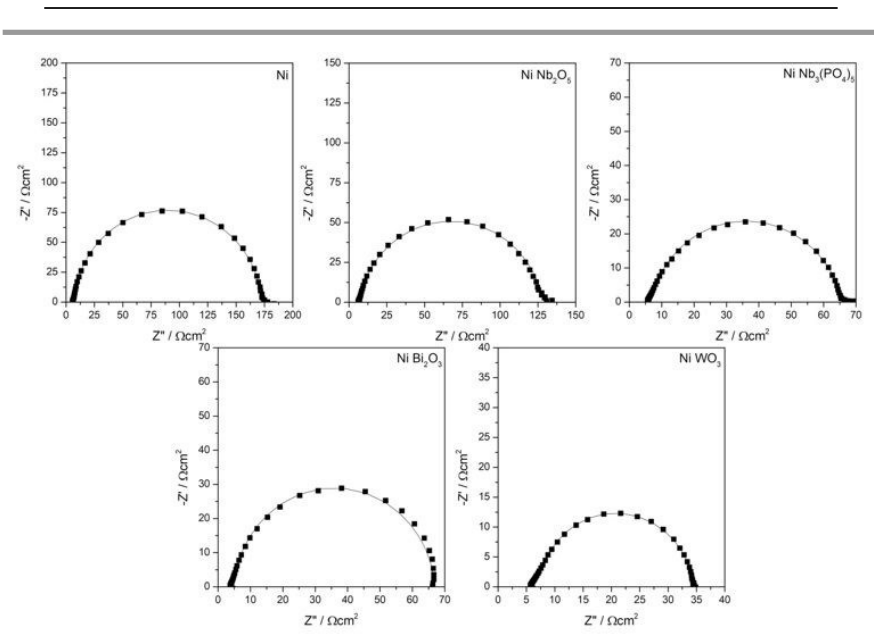

Figure 6. Comparison of EIS measured for Ni|SC electrodes at $298 \mathrm{~K}$ and $-1.2 \mathrm{~V}$ (Vs SCE) fitted with the AHEC1CPE equivalent circuit.

Figure S16 shows the EIS spectra in the complex plane for the catalysts measured at $298 \mathrm{~K}$ and different potentials while the inserts correspond to magnification of the Nyquist plots. It can be seen that increasing the overpotential systematically decreases the radius of the Nyquist plot indicating a dependence of the charge transfer resistance with the overpotential, which is common to find in the analysis of HER by impedance spectroscopy. ${ }^{62}$ Table 5 shows the parameters extracted from the selected model (AHEC1CPE). It can be seen that all SC catalysts have higher $\mathrm{CPE}_{1}$ values than that found in 
$\mathrm{Ni} \mid$ Watts, indicating that all have a greater electrochemica area, with $\mathrm{Ni} \mid \mathrm{WO}_{3}$ having the highest double layer capacitance. Interestingly, the higher $\mathrm{CPE}_{1}$ values are obtained for catalysts with higher surface roughness $\left(\mathrm{Ni} \mid \mathrm{WO}_{3}\right.$ and $\left.\mathrm{Ni} \mid \mathrm{Nb}_{2} \mathrm{O}_{5}\right)$. The surprisingly high $C P E_{1}$ value found for $\mathrm{Ni} \mid \mathrm{Nb}_{3}\left(\mathrm{PO}_{4}\right)_{5}$ could be explained by the additional surface reconstruction this material undergoes after ageing process, where electrochemical measurements induce a vein-like surface (Figure S18) that could contribute to a higher capacitance. Moreover, $\mathrm{Ni} \mid \mathrm{Nb}_{2} \mathrm{O}_{5}$ and $\mathrm{Ni} \mid \mathrm{WO}_{3}$ catalysts have the lowest $\mathrm{R}_{\mathrm{ct}}$ values - in agreement with their greatest catalytic activities seen by chronoamperometrywhile all $\mathrm{Ni} \mid \mathrm{SC}$ catalysts have a lower resistance $\left(R_{\mathrm{p}}\right)$ than the one found in $\mathrm{Ni}$ | Watts.

Finally, after the 4-hour ageing treatment of the electrocatalysts, we evaluated the behavior of the materials to analyze the potential structural changes due to the electrochemical process. From the SEM micrographs (Figure S17) we can see that the $\mathrm{Ni}\left|\mathrm{WO}_{3}, \mathrm{Ni}\right| \mathrm{Bi}_{2} \mathrm{O}_{3}$ and $\mathrm{Ni} \mid \mathrm{Nb}_{2} \mathrm{O}_{5}$ catalysts preserve their surface structure after short ageing, while the $\mathrm{Ni} \mid \mathrm{Nb}_{3}\left(\mathrm{PO}_{4}\right)_{5}$ catalyst develops a surface vein-like pattern (Figure S18). These structures were seen before on $\mathrm{Ni}$ based catalysts $^{64}$ and can be attributed to surface reconstruction which can considerably increase the exposed electrochemical area, thereby increasing the catalytic activity. Finally, EDS spectra after ageing indicate the catalysts preserve their bulk composition - despite the superficial changes they suffer (as in the case of $\mathrm{Ni} \mid \mathrm{Nb}_{3}\left(\mathrm{PO}_{4}\right)_{5}$ ) or potential solubility as it is predicted for $\mathrm{WO}_{3}{ }^{65}$ This structural stability can be confirmed by X-ray diffractograms measured after ageing where the presence of the semiconductors is also observed.

Table 5. Parameters of the modified AHEC1CPE equivalent circuit for the HER in $1.0 \mathrm{M}$ $\mathrm{KOH}$ at $298 \mathrm{~K}$ and $-1.1 \mathrm{~V}$ vs SCE.

\begin{tabular}{llllll}
\hline $\mathrm{Ni} \mid \mathrm{SC}$ & Watts & $\mathrm{Nb}_{2} \mathrm{O}_{5}$ & $\mathrm{Nb}_{3}\left(\mathrm{PO}_{4}\right)_{5}$ & $\mathrm{Bi}_{2} \mathrm{O}_{3}$ & $\mathrm{WO}_{3}$ \\
\hline $\mathrm{R}_{\mathrm{s}}\left(\Omega \mathrm{cm}^{2}\right)$ & 5.54 & 6.02 & 5.55 & 3.88 & 5.73 \\
$\left.\mathrm{CPE}_{1}(\mu \mathrm{Fcm})^{-2}\right)$ & 219 & 494 & 844 & 328 & 1370 \\
$\mathrm{CPE}_{1}-\mathrm{P}$ & 0.83 & 0.81 & 0.72 & 0.84 & 0.73 \\
$\mathrm{R}_{\mathrm{ct}}\left(\Omega \mathrm{cm}^{2}\right)$ & 5.51 & 14.2 & 139.7 & 497.3 & 7.83 \\
$\mathrm{C}_{\mathrm{p}}\left(\mu \mathrm{Fcm}^{-2}\right)$ & 22.0 & 41.8 & 5.17 & 2.30 & 147 \\
$\mathrm{R}_{\mathrm{p}}\left(\Omega \mathrm{cm}^{2}\right)$ & 1147 & 731.6 & 188.1 & 612.2 & 134.4 \\
\hline
\end{tabular}

\section{Conclusions}

We have developed a simple and binder-free method of synthesis to prepare four different $\mathrm{Ni}$ SC catalysts for hydrogen generation that can be easily scaled up for industrial production. We performed a comprehensive analysis of the materials relating different characterization features to their catalytic activity towards electrochemical generation of hydrogen. We have shown the catalysts have a higher catalytic activity towards the hydrogen generation in comparison to the conventional nickel electrodes currently used in conventional alkaline electrolyzers, obtaining an increase of hydrogen production of up to $115 \%$ (for the $\mathrm{Ni} \mid \mathrm{WO}_{3}$ catalyst) under short ageing conditions at $-1.5 \mathrm{~V}$ vs SCE. Durability studies show that the catalysts are stable over time and preserve their structure/composition under long-timeOlexposure OSto OGFER conditions -with the exception of $\mathrm{Ni} \mid \mathrm{Nb}_{3}\left(\mathrm{PO}_{4}\right)_{5}$ catalyst, which have suffered surface morphology changes that can be partly responsible for the increased catalytic activity of this material after ageing. Additionally, we found that the catalysts containing $\mathrm{Nb} \quad\left(\mathrm{Ni} \mid \mathrm{Nb}_{2} \mathrm{O}_{5}\right.$ and $\left.\mathrm{Ni} \mid \mathrm{Nb}_{3}\left(\mathrm{PO}_{4}\right)_{5}\right)$ show a considerable improved catalytic activity after ageing. This enhancement is mainly attributed to an increased rate of current change $(d j / d V)$, keeping the OP practically unchanged. Overall, these new Ni|SC composite catalysts can perform better than the conventional $\mathrm{Ni}$ | Watts, show great stability and durability during short ageing processes, are easy to synthesize and constitute an inexpensive alternative that can be easily adapted to prototypes for conventional alkaline electrolyzers.

\section{Conflicts of interest}

There are no conflicts to declare.

\section{Acknowledgements}

This work was supported by the Natural Sciences and Engineering Research Council of Canada, the Canada Foundation for Innovation, the Canada Research Chairs Program, the MINCYT-uOttawa bilateral agreement [project OT 17 02] (University of Ottawa and Argentine Ministry of Science). The authors acknowledge financial support from FONCYT PICT2017-0250 (Argentina) and PUE2017.

M.J.G. thanks CONICET for awarding her doctoral fellowship. V.B.L. thanks CONICET for awarding her postdoctoral fellowship. G.I.L. and E.A.F. are permanent research fellows of CONICET. The authors thank LANN laboratory at INFIQC for the assistance in Raman measurements.

\section{References}

1 1. S. Anantharaj and S. Noda, Small, 2020, 16, 1905779.

2 2. P. Shirvanian and F. van Berkel, Electrochem. Commun., 2020, 114, 106704.

3 3. M. Carmo, D. L. Fritz, J. Mergel and D. Stolten, Int. J. Hydrogen Energy, 2013, 38, 4901.

4 4. D. Xu, M. B. Stevens, M. R. Cosby, S. Z. Oener, A. M. Smith, L. J. Enman, K. E. Ayers, C. B. Capuano, J. N. Renner, N. Danilovic, Y. Li, H. Wang, Q. Zhang and S. W. Boettcher, ACS Catal., 2019, 9, 7.

5 5. L. Yu, Q. Zhu, S. W. Song, B. McElhenny, D. Z. Wang, C. Z. Wu, Z. J. Qin, J. M. Bao, Y. Yu, S. Chen and Z. F. Ren, Nat. Commun., 2019, 10.

6 6. C. L. Hu, L. Zhang and J. L. Gong, Energ. Environ. Sci., 2019, 12, 2620.

7 7. D. A. Harrington and B. E. Conway, Electrochim. Acta, 1987, 32, 1703.

8 8. B. Łosiewicz, A. Budniok, E. Rówiński, E. Łągiewka and A. Lasia, Int. J. Hydrogen Energy, 2004, 29, 145.

9 9. N. Mahmood, Y. D. Yao, J. W. Zhang, L. Pan, X. W. Zhang and J. J. Zou, Adv. Sci., 2018, 5.

10 10. X. Li, P. F. Liu, L. Zhang, M. Y. Zu, Y. X. Yang and H. G. Yang, Chem. Commun., 2016, 52, 10566. 
11 11. M. Schalenbach, G. Tjarks, M. Carmo, W. Lueke, M Mueller and D. Stolten, J. Electrochem. Soc., 2016, 163, F3197.

12 12. M. Y. Wang, Z. Wang, X. Z. Gong and Z. C. Guo, Renew. Sust. Energ. Rev., 2014, 29, 573.

13 13. R. Phillips and C. W. Dunnill, RSC Adv., 2016, 6, 100643.

14 14. Q. Liu, J. Q. Tian, W. Cui, P. Jiang, N. Y. Cheng, A. M. Asiri and X. P. Sun, Angew. Chem. Int. Ed., 2014, 53, 6710.

15 15. Y. Liang, Y. Li, H. Wang and H. Dai, J. Am. Chem. Soc., 2013, 135, 2013.

16 16. E. A. Franceschini and G. I. Lacconi, Electrocatal., 2018, 9, 47.

17 17. E. A. Franceschini, M. J. Gomez and G. I. Lacconi, J. Energy Chem., 2019, 29, 79.

18 18. J. Mohammed-Ibrahim and X. M. Sun, J. Energy Chem., 2019, 34, 111.

19 19. E. W. Brooman and A. T. Kuhn, J. Electroanal. Chem. Interfacial Electrochem., 1974, 49, 325.

20 20. E. Franceschini, A. Hainer and A. E. Lanterna, Int. J. Hydrogen Energy, 2019, 44, 31940.

21 21. M. J. Gomez, E. A. Franceschini and G. I. Lacconi, Electrocatal., 2018, 9, 459.

22 22. M. J. Gómez, L. A. Diaz, E. A. Franceschini, G. I. Lacconi and G. C. Abuin, J. Appl. Electrochem., 2019, 49, 1227

23 23. B. W. Wang, A. E. Lanterna and J. C. Scaiano, ACS Catal., 2017, 7, 8487.

24 24. B. Wang, J. Durantini, J. Nie, A. E. Lanterna and J. C. Scaiano, J. Amer. Chem. Soc., 2016, 138, 13127.

25 25. B. N. Nunes, O. F. Lopes, A. O. T. Patrocinio and D. W. Bahnemann, Catalysts, 2020, 10.

26 26. K. Gurunathan, Int. J. Hydrogen Energy, 2004, 29, 933.

27 27. P. Maruthamuthu, K. Gurunathan, E. Subramanian and M. V. C. Sastri, Int. J. Hydrogen Energy, 1993, 18, 9.

28 28. P. Maruthamuthu, M. Ashokkumar, K. Gurunathan, E. Subramanian and M. V. C. Sastri, Int. J. Hydrogen Energy, 1989, 14, 525.

29 29. P. Maruthamuthu, K. Gurunathan, E. Subramanian and M. V. C. Sastri, Int. J. Hydrogen Energy, 1994, 19, 889.

30 30. S. Kumaraguru, G. G. Kumar, S. Shanmugan, S. Mohan and R. M. Gnanamuthu, J. Alloys Compd., 2018, 753, 740.

31 31. S. M. A. Shibli, V. R. Anupama, P. S. Arun, P. Jineesh and L. Suji, Int. J. Hydrogen Energy, 2016, 41, 10090.

32 32. M. M. Bruno, E. A. Franceschini, G. A. Planes and H. R. Corti, J. Appl. Electrochem., 2010, 40, 257.

33 33. A. H. W. Ngan and R. E. Smallman, Physical metallurgy and advanced materials, Butterworth Heinemann, Amsterdam, 7th edn., 2007.

34 34. L. B. Wang, Y. T. Zhao, C. H. Jiang, V. Ji, M. Chen, K. Zhan and F. Moreira, J. Alloys Compd., 2018, 754, 93.

35 35. E. A. Franceschini, G. I. Lacconi and H. R. Corti, Electrochim. Acta, 2015, 159, 210.

36 36. D. G. Lamas, O. de Oliveira Neto, G. Kellermann and A. F. Craievich, in Nanocharacterization techniques, eds. F. b. de Lima Leite, M. Ferreira, O. N. Oliveira and A. L. da Róz, William Andrew, Cambridge, MA, 2017, p. 111.

37 37. P. Quaino, F. Juarez, E. Santos and W. Schmickler, Beilstein J. Nanotechnol., 2014, 5, 846.

38 38. D. S. Hall, C. Bock and B. R. MacDougall, J. Electrochem. Soc., 2013, 160, F235.

39 39. D. S. Hall, D. J. Lockwood, S. Poirier, C. Bock and B. R. MacDougall, ACS Appl. Mater. Interfaces, 2014, 6, 3141.

40 40. J. M. Jehng and I. E. Wachs, Chem. Mater., 1991, 3, 100.

41 41. P. Torruella, C. Coll, G. Martín, L. López-Conesa, M. Vila, C. Díaz-Guerra, M. Varela, M. L. Ruiz-González, J. Piqueras, F. Peiró and S. Estradé, J. Phys. Chem. C, 2017, 121, 24809.

42 42. L. Xu, M. L. Yin and S. Liu, Sci. Rep., 2014, 4, 6745.

43 43. M. C. Biesinger, L. W. M. Lau, A. R. Gerson and R. S. C. Smart, Phys. Chem. Chem. Phys., 2012, 14, 2434.
44 44. H. Konno, X-ray Photoelectron Spectroscopy in Materials Science and Engineering of Carbon, eds|: M 1 dnagaki Kang, Butterworth-Heinemann, 2016, pp. 153.

45 45. S. Trasatti and O. A. Petrii, J. Electroanal. Chem., 1992, 327, 353.

46 46. E. A. Franceschini, G. I. Lacconi and H. R. Corti, J. Energy Chem., 2017, 26, 466.

47 47. I. Bianchi, E. Guerrini and S. Trasatti, Chem. Phys., 2005, 319, 192.

48 48. A. Đukić, V. Alar, M. Firak and S. Jakovljević, J. Alloys Compd., 2013, 573, 128.

49 49. Š. Trafela, J. Zavašnik, S. Šturm and K. Ž. Rožman, Electrochim. Acta, 2019, 309, 346.

50 50. L. A. Dahonog and M. D. L. Balela, Mater. Today: Proc., 2020, 22, 268.

51 51. G. Kreysa, B. Hakansson and P. Ekdunge, Electrochim. Acta, 1988, 33, 1351.

52 52. K. I. Siwek, S. Eugénio, D. M. F. Santos, M. T. Silva and M. F. Montemor, Int. J. Hydrogen Energy, 2019, 44, 1701.

53 53. J. Jiang and A. Kucernak, J. Electroanal. Chem., 2002, 520, 64.

54 54. J. W. Guo, T. S. Zhao, J. Prabhuram, R. Chen and C. W. Wong, Electrochim. Acta, 2005, 51, 754.

55 55. E. A. Franceschini, G. I. Lacconi and H. R. Corti, Int. J. Hydrogen Energy, 2016, 41, 3326.

56 56. D. S. Hall, D. J. Lockwood, S. Poirier, C. Bock and B. R. MacDougall, J. Phys. Chem. A, 2012, 116, 6771.

57 57. R. D. Armstrong and M. Henderson, J. Electroanal. Chem., 1972, 39, 81.

58 58. E. Daftsis, N. Pagalos, A. Jannakoudakis, P. Jannakoudakis, E. Theodoridou, R. Rashkov, M. Loukaytsheva and $\mathrm{N}$. Atanassov, J. Electrochem. Soc., 2003, 150, C787.

59 59. J. Panek, A. Serek, A. Budniok, E. Rowinski and E. Lagiewka, Int. J. Hydrogen Energy, 2003, 28, 169.

60 60. Z. Kerner and T. Pajkossy, Electrochim. Acta, 2000, 46, 207.

61 61. A. Lasia and A. Rami, J. Electroanal. Chem., 1990, 294, 123.

62 62. L. L. Chen and A. Lasia, J. Electrochem. Soc., 1991, 138, 3321.

63 63. C. Hitz and A. Lasia, J. Electroanal. Chem., 2001, 500, 213.

64 64. X. Cao, D. Jia, D. Li, L. Cui and J. Liu, Chem. Eng. J., 2018, 348, 310.

65 65. M. Pourbaix, Atlas of electrochemical equilibria in aqueous solutions, Pergamon Press, Brussels, 1967. 66 


\section{TABLE OF CONTENTS GRAPHIC}

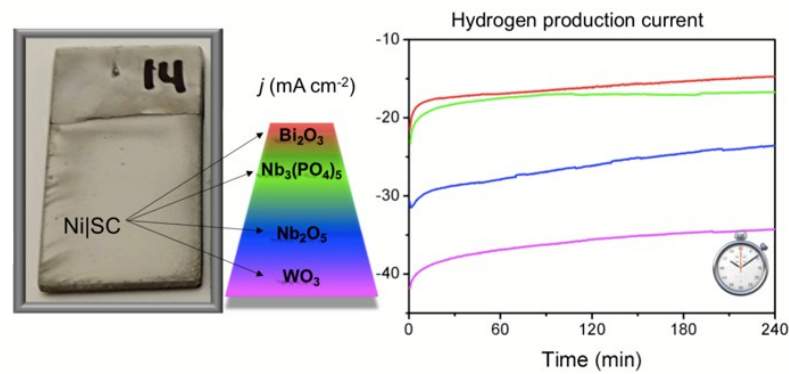

A series of Ni-semiconductor composites are electrodeposited onto low-cost stainless-steel plates and used as electrodes for hydrogen generation from water; showing superb electrocatalytic activity over time. 